\title{
Brachytherapy in breast cancer: an effective alternative
}

\author{
Janusz Skowronek ${ }^{1,2}$, Adam Chichet ${ }^{1}$ \\ ${ }^{1}$ Brachytherapy Department, Greater Poland Cancer Center, Poznań, Poland \\ ²Electroradiology Department, Poznan University of Medical Sciences, Poznań, Poland
}

\begin{abstract}
Breast conserving surgery (BCS) with following external beam radiation therapy (EBRT) of the conserved breast has become widely accepted in the last decades for the treatment of early invasive breast cancer. The standard technique of EBRT after BCS is to treat the whole breast up to a total dose of 42.5 to 50 Gy. An additional dose is given to treated volume as a boost to a portion of the breast. In the early stage of breast cancer, research has shown that the area requiring radiation treatment to prevent the cancer from local recurrence is the breast tissue that surrounds the area where the initial cancer was removed. Accelerated partial breast irradiation (APBI) is an approach that treats only the lumpectomy bed plus a 1-2 cm margin rather than the whole breast and as a result allows accelerated delivery of the radiation dose in four to five days. There has been a growing interest for APBI and various approaches have been developed under phase I-III clinical studies; these include multicatheter interstitial brachytherapy, balloon catheter brachytherapy, conformal external beam radiation therapy (3D-EBRT) and intra-operative radiation therapy (IORT). Balloon-based brachytherapy approaches include MammoSite, Axxent electronic brachytherapy, Contura, hybrid brachytherapy devices. Another indication for breast brachytherapy is reirradiation of local recurrence after mastectomy. Published results of brachytherapy are very promising. We discuss the current status, indications, and technical aspects of breast cancer brachytherapy.
\end{abstract}

Key words: APBI, boost, breast cancer, brachytherapy, recurrence.

\section{Purpose}

Breast cancer is the most frequently detected cancer in women in developed countries and its incidence ranges from 25 to $30 \%$ of all cancers in women. Average age of breast cancer patients ranges between 45 and 65 , in recent years there has been a noticeable trend to lower the average age of incidence [1]. Breast conserving therapy $(\mathrm{BCT})$, consisting of conservative surgery (BCS), radiotherapy (whole breast radiation therapy, WBRT) \pm brachytherapy and optional adjuvant chemotherapy, is a standard radical treatment for a vast majority of breast cancer patients. Breast conserving therapy is a good alternative to mastectomy in treatment of early invasive breast cancer [2-5]. Due to further advances in radiotherapy techniques and knowledge of the biology of breast cancer, in addition to the standard methods of combination therapy (WBRT and "boost"), the application of accelerated partial breast irradiation (APBI) as a radical treatment in selected cases is increasing [6-9]. This method of radiation therapy is used in a selected group of patients in the early stages of the disease $[3,10-15]$. The main reason for the introduction of $\mathrm{APBI}$ was the assumption that it leads to equivalent local control rates with less toxicity of treatment compared with WBRT after BCS in the selected group of patients. The advantage of this method is also shortening the time from 5-7 weeks of treatment (WBRT + boost) to 4-5 days of APBI. It is supposed to be also able to reduce the rate of complications: radiation-induced reactions, telangiectasia and fibrosis [16]. Treatment techniques, principles of patient selection for this method, results of treatment, and current recommendations of GEC-ESTRO (Groupe Européen de Curiethérapie - European Society for Radiotherapy and Oncology), ABS (American Brachytherapy Society) and ASTRO (American Society for Radiation Oncology ) are presented.

\section{Rationale for the use of a boost after breast conserving surgery and whole breast radiation therapy [17]}

The goal of irradiation is to minimize the risk of a local relapse within the treated breast, especially in the area of a tumor bed which is a target volume for

Corresponding author: 
brachytherapy. There are many methods of increasing the dose to the tumor bed (boost) [17-19]. The best approach is chosen depending on clinical and morphological criteria, patient's will and institutional resources and protocols. Modern interstitial multi-catheter high-doserate (HDR) brachytherapy offers conformal and accurate irradiation of the target volume, provided that there are surgical clips left in the operated breast and the treatment planning system is computed tomography (CT) based. Patient's age of < 50 years; close, microscopically positive or unknown surgical margins; and the presence of an extensive intraductal component are accepted indications for boost irradiation [20-22]. Randomized "boost vs. no boost" trials revealed that there is an evident benefit from administering an additional dose to the tumor bed. The boost reduces 5-year local recurrence rates from $7.3-13.3 \%$ to $3.6-6.3 \%(p=0.04-0.0001)$ [23-25]. Polgár et al. also summarized the results of many different HDR brachytherapy series worldwide, in which in total 1776 patients, a 5-year local recurrence rate of 0-9\% (mean 5.5\%) was achieved [22].

\section{Rationale for accelerated partial breast irradiation}

The results of studies examining the efficacy of BCS followed by WBRT showed that a very large percentage of local recurrence arises in the immediate vicinity of the original location of the tumor. At least five prospective randomized studies examining the percentage of local recurrences after radiotherapy of the whole breast were published and it was found that $69-90 \%$ of recurrences occur in the immediate vicinity of the primary tumor (Table I). In other studies, the percentage of recurrences in other quadrants than in the one being treated or contralateral breast was $0.9-3.5 \%$ in prospective studies and $2-5 \%$ in retrospective studies (Table II). This was the basic argument for the use of brachytherapy alone after BCS treatment in a strictly selected group of patients $[1,4,13$, $33,34]$. Another advantage of this method pointed out by many authors is also shortening of the treatment duration of 5-7 weeks (conventional EBRT) to 4-5 days, what is important particularly for working women and living far away from the cancer center and older patients [1]. Offeresen et al. [35] in the summary pointed out that in the U.S., socio-economic factors affect the type of surgery - poorer women (e.g. paying a lower insurance premium) and/or living far from the radiotherapy center choose mastectomy, even after qualifying for the BCS. In some areas, up to $25 \%$ of older women after BCS are not irradiated for these reasons. After examination of 175,000 patients with early breast cancer it was found that in 1992-2003, the percentage of BCS increased from $41 \%$ to $60 \%$, while the proportion of patients irradiated after BCS decreased from $79 \%$ to $71 \%$. Undoubtedly it affects the increased risk of local recurrences after BCS. Similar conclusions were reached by Njeh et al. [36] - in this article, they listed factors affecting radiotherapy (RT) decision: convenience, accessibility, cost, distance from the center of RT, lack of transportation, lack of social support, movement difficulties of patients, doctor bias, age of the patient, fear of radiation. Also in Japan, only about $70 \%$ of patients are treated with radiotherapy after BCS, for similar reasons as in the U.S.

\section{Indications for boost}

Brachytherapy is appropriate to deliver an additional conformal boost dose to the surgical bed plus margin following standard WBRT. Ideally chosen when the physician believes that the boost dose delivery to the target is better accomplished with brachytherapy as opposed to electrons and would be dependent on the size/ shape/location of the lumpectomy cavity in relation to

Table I. Spatial pattern of ipsilateral breast relapse (IBTR) in patients enrolled in randomized trials testing the effect of the whole breast radiotherapy [1]

\begin{tabular}{|c|c|c|c|}
\hline $\begin{array}{l}\text { Trial (time of primary } \\
\text { treatment) }\end{array}$ & $\begin{array}{l}\text { Median follow- } \\
\text { up (range) }\end{array}$ & $\begin{array}{l}\text { Recurrence number (total } \\
\text { number of patients) }\end{array}$ & Pattern of IBTR \\
\hline $\begin{array}{l}\text { NSABP B-06 } \\
(1976-1984)[10]\end{array}$ & $\begin{array}{l}39(5-95) \\
\text { months }\end{array}$ & $110(1108)$ & $\begin{array}{l}86 \% \text { within or close to the quadrant of the index cancer } \\
14 \% \text { more diffuse within the breast }\end{array}$ \\
\hline $\begin{array}{l}\text { Uppsala-Orebro } \\
(1981-1988)[11]\end{array}$ & 10 years & $57(381)$ & $\begin{array}{l}69 \% \text { in the surgical field } \\
3.6 \% \text { in the cuticular scar } \\
3.6 \% \text { in the skin overlying the surgical field } \\
23.6 \% \text { in the breast parenchyma outside the field of } \\
\text { surgery }\end{array}$ \\
\hline $\begin{array}{l}\text { Ontario Clinical Oncology } \\
\text { Group (1984-1989) [12] }\end{array}$ & 43 months & $131(837)$ & $86 \%(83 \%$ with RT) at the site of primary surgery \\
\hline $\begin{array}{l}\text { Milan III } \\
(1987-1989)[13]\end{array}$ & 9 years & $75(579)$ & $\begin{array}{l}85 \%(84 \% \text { with RT) in the scar area } \\
15 \%(16 \% \text { with RT) in other quadrants }\end{array}$ \\
\hline $\begin{array}{l}\text { SweBCG 91-RT } \\
(1991-1997)[14]\end{array}$ & 5 years & $104(1178)$ & $\begin{array}{l}90 \% \text { in the same quadrant as the previous tumour } \\
10 \% \text { in other quadrants }\end{array}$ \\
\hline
\end{tabular}


Table II. Spatial pattern of ipsilateral breast relapse (IBTR) in patients treated with breast conserving surgery plus whole breast radiotherapy [1]

\begin{tabular}{|c|c|c|c|c|}
\hline Authors, studies & $\begin{array}{l}\text { Median follow-up } \\
\text { (range) }\end{array}$ & $\begin{array}{l}\text { Local recurrence } \\
\text { rate }(\%)\end{array}$ & $\begin{array}{l}\text { Recurrence rate outside of } \\
\text { the treated quadrant (\%) }\end{array}$ & $\begin{array}{l}\text { Recurrence rate in } \\
\text { the second breast (\%) }\end{array}$ \\
\hline \multicolumn{5}{|c|}{ Retrospective clinical trials (BCS + EBRT) } \\
\hline Kurtz et al. [15] & 11 (5-24 years) & 11 & 2 & 6 \\
\hline Freedman et al. [26] & $\begin{array}{l}5 \text { years } \\
10 \text { years } \\
15 \text { years }\end{array}$ & $\begin{array}{c}3 \\
7 \\
13\end{array}$ & $\begin{array}{l}1 \\
2 \\
6\end{array}$ & $\begin{array}{c}3 \\
7 \\
13\end{array}$ \\
\hline Krauss et al. [27] & $\begin{array}{l}5 \text { years } \\
10 \text { years } \\
15 \text { years }\end{array}$ & $\begin{array}{c}2 \\
7 \\
10\end{array}$ & $\begin{array}{c}0.1 \\
2 \\
3\end{array}$ & $\begin{array}{c}4 \\
9 \\
12 \\
\end{array}$ \\
\hline Veronesi et al. [28] & 8.5 years & 6.8 & 1.4 & 5 \\
\hline \multicolumn{5}{|c|}{ Prospective trials (BCS + EBRT) } \\
\hline NSABP B-06 [18] & 39 (5-95) months & 2.7 & 0.7 & 9.4 \\
\hline Uppsala-Orebro trial [11] & 10 years & 8.5 & 2.1 & 10.5 \\
\hline Scottish trial [29] & 5.7 years & 5.8 & 1.4 & 1 \\
\hline Milan III [28] & 9 years & 5.4 & 1.3 & 3.4 \\
\hline NSABP B-21 [30] & 8 years & 9.3 & 2.3 & 5.4 \\
\hline SweBCG 91-RT [14] & 61 (10-98) months & 4.4 & 1.1 & 3.4 \\
\hline GBCSG trial [31] & 5.9 years & 4.2 & 1 & 2.1 \\
\hline ABCSG study 8 [32] & 53.8 months & 0.5 & 0.1 & 0.5 \\
\hline
\end{tabular}

$\mathrm{BCS}$ - breast conserving surgery, EBRT - external beam radiation therapy

the size/shape of the breast [37]. While the external electron beam boost usually includes the skin and subcutaneous vessels, the interstitial implant represents a more conformal technique, which offers the advantage of lower rates of late side effects, in particular of skin telangiectasia and skin fibrosis [38-41]. Retrospective and prospective trials showed an increase in local control and an increase in survival compared to patients with no boost [25, 42-44]. In the European Organisation for Research and Treatment of Cancer (EORTC) "boost versus no boost" randomized trial 22881/10882, 2661 patients enrolled in the boost arm were analyzed. All patients received 50 Gy WBRT and a boost dose of

Table III. American Brachytherapy Society and American Society of Breast Surgeons selection criteria and the Eligibility Criteria for NSABP B-39/RTOG 0413 Trial [48]

\begin{tabular}{lccc}
\hline & ABS & ASBS & $\begin{array}{c}\text { NSABP B-39 } \\
\text { RTOG 0413 }\end{array}$ \\
\hline Age & $\geq 50$ & $\geq 45$ & $\geq 18$ \\
\hline Histology & $\begin{array}{c}\text { Unifocal, in- } \\
\text { vasive ductal } \\
\text { cancer }\end{array}$ & $\begin{array}{c}\text { Invasive } \\
\text { ductal cancer } \\
\text { or DCIS }\end{array}$ & $\begin{array}{c}\text { Invasive ad- } \\
\text { enocarcinoma } \\
\text { or DCIS }\end{array}$ \\
\hline Tumor size & $\leq 3 \mathrm{~cm}$ & $\leq 3 \mathrm{~cm}$ & $\leq 3 \mathrm{~cm}$ \\
\hline $\begin{array}{l}\text { Surgical } \\
\text { margins }\end{array}$ & $\begin{array}{c}\text { Negative } \\
\text { microscopic } \\
\text { margins }\end{array}$ & $\begin{array}{c}\text { Negative } \\
\text { microscopic } \\
\text { margins }\end{array}$ & $\begin{array}{c}\text { Negative } \\
\text { microscopic } \\
\text { margins }\end{array}$ \\
\hline $\begin{array}{l}\text { Number of } \\
\text { involved } \\
\text { lymph nodes }\end{array}$ & 0 & 0 & $0-3$ \\
\hline
\end{tabular}

16 Gy to the primary tumor bed after microscopically complete tumorectomy. Sixty-three percent of patients received a boost dose with electrons, $28 \%$ with photon beams, and $9 \%$ with interstitial brachytherapy (BT). At 5 years of follow-up, local recurrences were seen in $4.8 \%$ of patients who received an electron boost, in $4 \%$ of cases with a photon boost received, and in $2.5 \%$ of patients who underwent BT. No differences were noted in terms of late toxicities $[45,46]$.

\section{Indications for accelerated partial breast irradiation}

Recommendations of the ABS and the American Society of Breast Surgeons (ASBS) regarding the qualifications for APBI are shown in Table III [47, 48], while the GECESTRO recommendations are posted in Table IV [49].

\section{Indications for brachytherapy of local recurrence}

Thoracic wall brachytherapy is performed with a moulded cast or standard interstitial catheters for breast cancer recurrences after mastectomy and previous irradiation to the thoracic wall. Limited recurrences can also be treated by interstitial implantation, definitively or after surgical resection [3]. Brachytherapy represents an alternative to ultraradical surgery or external-beam reirradiation for the assurance of resection 
Table IV. GEC-ESTRO recommendations for patient selection for accelerated partial-breast irradiation [49]

\begin{tabular}{|c|c|c|c|}
\hline Characteristic & $\begin{array}{l}\text { A) Low-risk group - good } \\
\text { candidates for APBI }\end{array}$ & $\begin{array}{l}\text { B) Intermediate-risk group - } \\
\text { possible candidates for APBI }\end{array}$ & $\begin{array}{l}\text { C) High-risk group - } \\
\text { contraindications for APBI }\end{array}$ \\
\hline Age & $>50$ years & $40-50$ years & $<40$ years \\
\hline Histology & $\begin{array}{l}\text { IDC, mucinous, tubular, medul- } \\
\text { lary, and colloid cc. }\end{array}$ & $\begin{array}{l}\text { IDC, ILC, mucinous, tubular, } \\
\text { medullary, and colloid cc. }\end{array}$ & - \\
\hline ILC & Not allowed & Not allowed & - \\
\hline Associated LCIS & Allowed & Allowed & - \\
\hline DCIS & Not allowed & Allowed & - \\
\hline HG & Any & Any & - \\
\hline Tumour size & pT1-2 (<30 mm) & pT1-2 (<30 mm) & pT2 (> $30 \mathrm{~mm}), \mathrm{pT} 3, \mathrm{~T} 4$ \\
\hline Surgical margin & Negative $(>2 \mathrm{~mm})$ & Negative, but close $(<2 \mathrm{~mm})$ & Positive \\
\hline Multicentricity & Unicentric & Unicentric & Multicentric \\
\hline Multifocality & Unifocal & $\begin{array}{c}\text { Multifocal (limited within } 2 \mathrm{~cm} \\
\text { of the index lesion) }\end{array}$ & $\begin{array}{l}\text { Multifocal ( }>2 \mathrm{~cm} \text { from } \\
\text { the index lesion) }\end{array}$ \\
\hline EIC & Not allowed & Not allowed & Present \\
\hline LVI & Not allowed & Not allowed & Present \\
\hline ER, PR Status & Any & Any & - \\
\hline Nodal Status & pNO (SLNB or ALND*) & pN1mi, pN1a (by ALND*) & $\begin{array}{l}\text { pNx;PpN2a (4 or more } \\
\text { positive nodes) }\end{array}$ \\
\hline Neoadjuvant chemotherapy & Not allowed & Not allowed & If used \\
\hline
\end{tabular}

margins. Isolated local chest wall recurrence of breast cancer can be properly cured with minimal side effects by limited tumorectomy plus 20-30 Gy perioperative brachytherapy. Interstitial high-dose-rate after-loading brachytherapy is indicated for tumors with deep infiltration. For geometric optimization and the achievement of dose homogeneity, good results have been obtained by means of CT-based treatment planning [50]. There are also a few reports about brachytherapy in the treatment of local relapses after BCS [51].

\section{Contraindications}

The list includes clinical stage III or IV, no evaluation of surgical margins, presence of extensive intraductal component (EIC), Paget's disease, infiltration or other changes in skin, present contralateral breast cancer (or in the past), previous other cancers (within 5 years from eligibility for the study) with the exception of skin cancer and 0 or Ist International Federation of Gynecology and Obstetrics (FIGO) cervical cancer (previous), pregnancy or lactation period, connective tissue disorders, collagen diseases, genetic or metabolic diseases proceeding with hypersensitivity to radiation such as Ataxia telangiectasia or similar, disorder or mental diseases, anticipated difficulties with carrying out of brachytherapy $[1,3,5,9]$. For thoracic wall recurrences (mould technique), target areas larger than $40 \mathrm{~cm}^{2}$ or lesions thicker than $5 \mathrm{~mm}$.

\section{Brachytherapy techniques}

Currently, several techniques are applied: 1) interstitial brachytherapy (HDR), pulsed-dose-rate (PDR), permanent implants - in clinical studies); 2) brachytherapy using the balloons (MammoSite, Contura); 3) hybrid brachytherapy devices (strut adjusted volume implant [SAVI] applicator). The latter two are performed in APBI only. Below we will discuss the basic principles of brachytherapy techniques.

\section{Patient qualification for brachytherapy techniques $[1,52]$}

Before preparing the treatment plan a careful evaluation of tumor size and location should be made (clinical examination, mammography, ultrasonography [US], sometimes magnetic resonance imaging [MRI]), also the stage of disease should be determined according to TNM and detailed histopathological examination should be performed. In the course of conservative treatment, it is advisable to leave 4 to 6 clips on the border of tissue removed in the axis of anterior-posterior, posterio- 
medial and sagittal and up and down, which will facilitate the preparation of the brachytherapy treatment plan. Clipping of the tumor bed is considered by many authors as the most precise factor determining the accuracy of brachytherapy. In the treatment planning using BT the following is also helpful: description of surgical procedures specifying the location of the scar in relation to the tumor bed, postoperative mammography, sometimes an X-ray image of the tumor bed or postoperative ultrasound.

\section{Interstitial multicatheter brachytherapy [1]}

Currently, two brachytherapy techniques are used in breast cancer brachytherapy: HDR and PDR:

\section{Perioperative application of catheters}

Brachytherapy using interstitial applicators can be performed in two ways. Perioperative brachytherapy involves the assumption of flexible applicators during surgery in place of the tumor bed. In this method, BT is applied immediately during BCS. The advantage of the perioperative technique is the need for only one general anesthesia (implantation of applicators takes place during surgery), resulting in reducing overall treatment time and the ability to precisely determine the location of the tumor visible during surgery. During a lumpectomy/quadrantectomy the surgeon provides surgical clips (should be 6) to determine the tumor bed, later they are helpful in treatment planning. Insertion of applicators requires precision, experience and basic knowledge in the field of radiation from the surgeon. The limitation of perioperative "boost" is the lack of the final histopathological examination - the risk of incorrect BT qualification can be leveled by precise clinical staging before the procedure, intraoperative histological examination and the necessary implementation

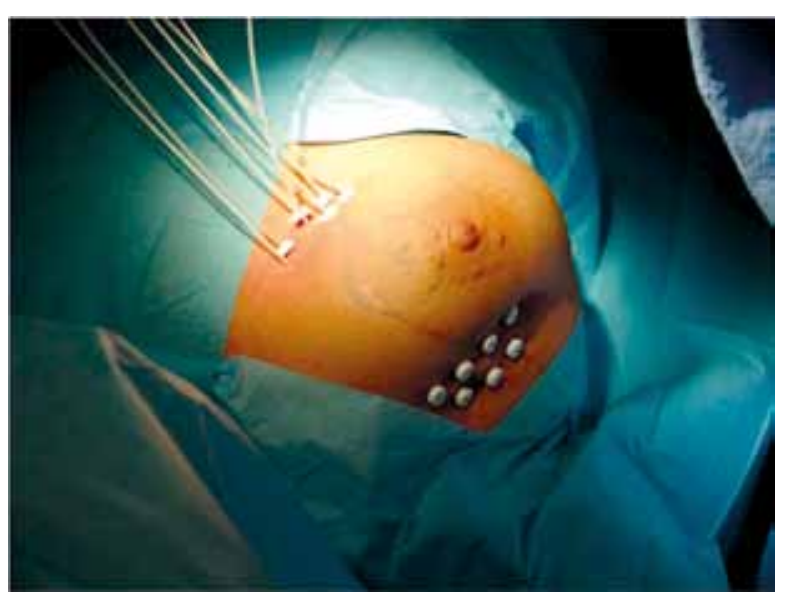

Fig. 1. Interstitial brachytherapy for breast cancer - implantation of 7 flexible applicators attached to the skin with buttons, the tumor bed measured by ultrasound of the sentinel-lymph-node biopsy (SLNB). The irradiated area is limited to the surgical bed with a $1-1.5 \mathrm{~cm}$ margin depending on the technique.

\section{Application of catheters after BCS}

Applicators are often implanted after healing of the surgical scar and after receiving the final histopathological diagnosis in 2-4 weeks after surgery. The radiation oncologist inserts applicators after visualization of the tumor bed using the X-ray (the location of surgical clips) and using ultrasound, in general or local anesthesia (depending on the experience of the center). Location of applicators on the skin with subcutaneous tissue and part of the breast is anesthetized with a solution of lidocaine or Xylocaine (2\%), while analgesics are administered intravenously. General anesthesia involves standard procedures. After determining the shape and position of the tumor bed, a correct template is selected, the number of planes, the distance between the applicators and the active length for stepping source is proposed. The number of implanted applicators has to be determined individually, depending on breast size, location of the tumor bed, and type of surgery (tumorectomy, quadrantectomy). Frequently there are from 7 to over a dozen applicators. Figure 1 shows images of applicators implanted in a patient with breast cancer after quadrantectomy, covering the upper external quadrant. Figures 2 and 3 present examples of treatment plans and applicators used in interstitial BT.

\section{Balloon brachytherapy (MammoSite, Contura) and hybrid strut adjusted volume implant applicators [1]}

This technique was intended to reduce the technical difficulties associated with EBRT treatment plan-

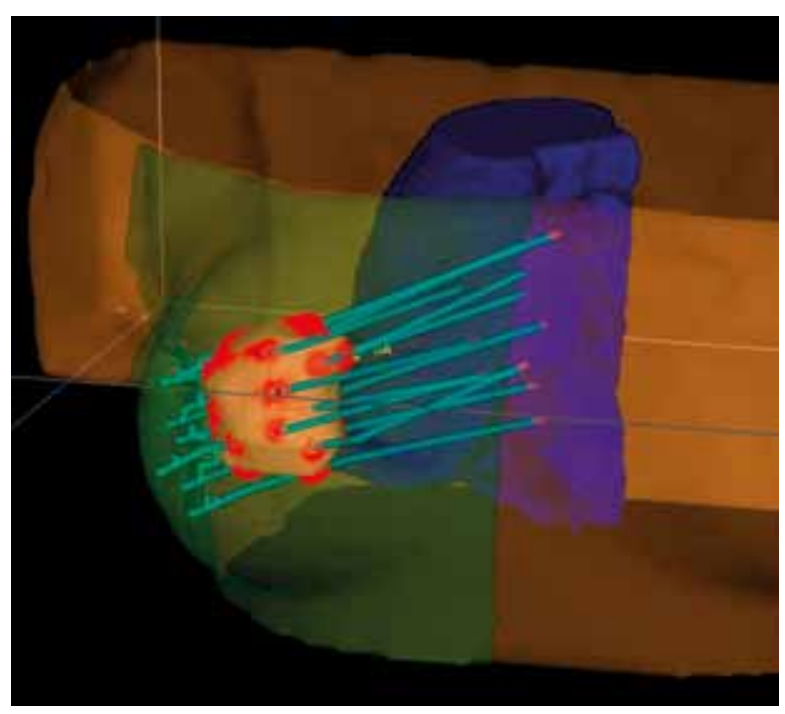

Fig. 2. Example of 3D treatment plan for breast cancer, indicating target, applicators, and critical organs (plan prepared by Oncentra Prostate ${ }^{\circledR}$ ) 
ning and application of many interstitial applicators [54]. The balloon applicator consists of a silicone balloon catheter containing a channel for filling the balloon and 1 to 8 channels to introduce radioisotope (Figures 4A-B). Strut adjusted volume implant applicator does not include a balloon but only applicators to adapt to the shape of the box (Figures 5A-B). Balloon technique is in principle applicable in APBI with resignation of WBRT after surgery. High-dose-rate sources are used in this technique. Balloon applicators may be placed in the bed of the tumor during the BCS (rarely) or 2-4 weeks after surgery with the help of ultrasound. Previously published results suggest a satisfactory treatment outcome (as measured by the percentage of local failure), and good cosmetic results (80\% to $93 \%$ of patients) [55-58]. So far we have not had randomized studies comparing this technique treatment with interstitial BT. Maybe the response will bring the results of Phase III Trial (NSABP B-39/RTOG 0413) conducted by

A
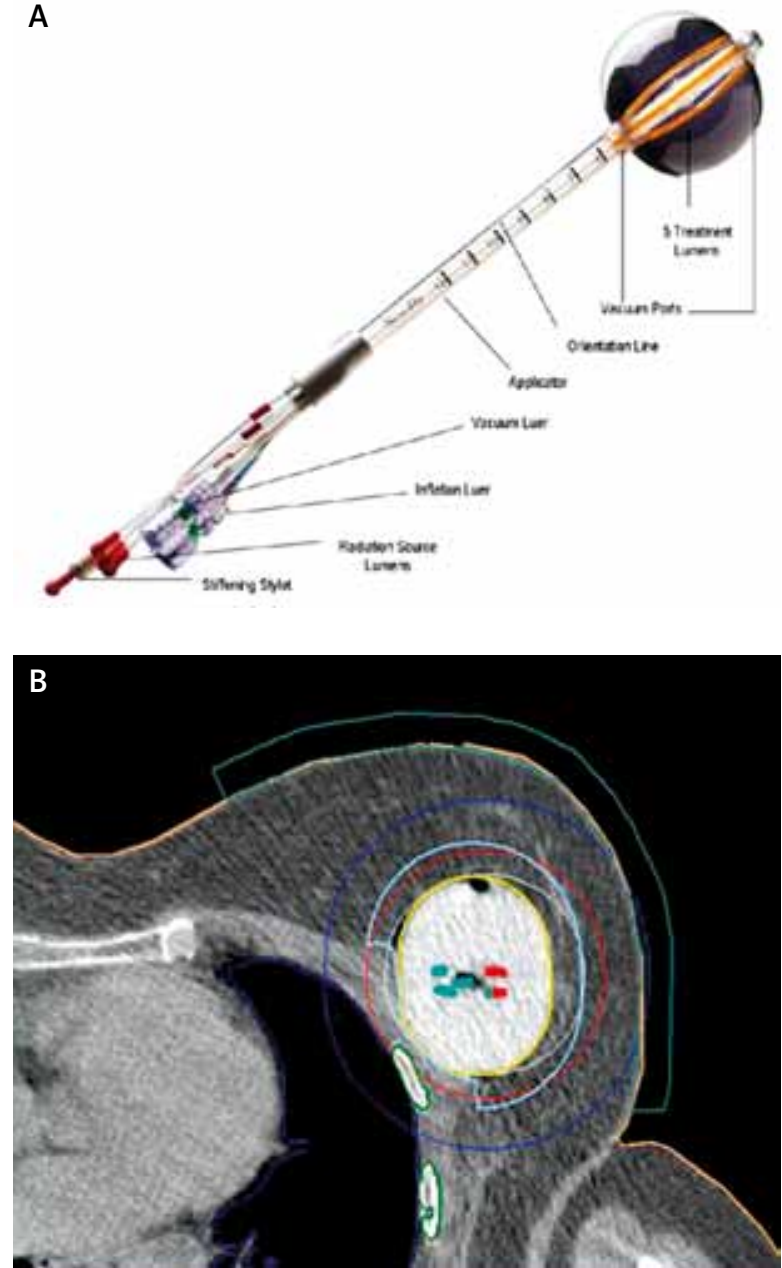

Fig. 4. A) Contura balloon applicator (SenoRx ${ }^{\oplus}$ [36]. B) Contura balloon applicator on CT section with the distribution of isodoses, 5 channels for iridium visible

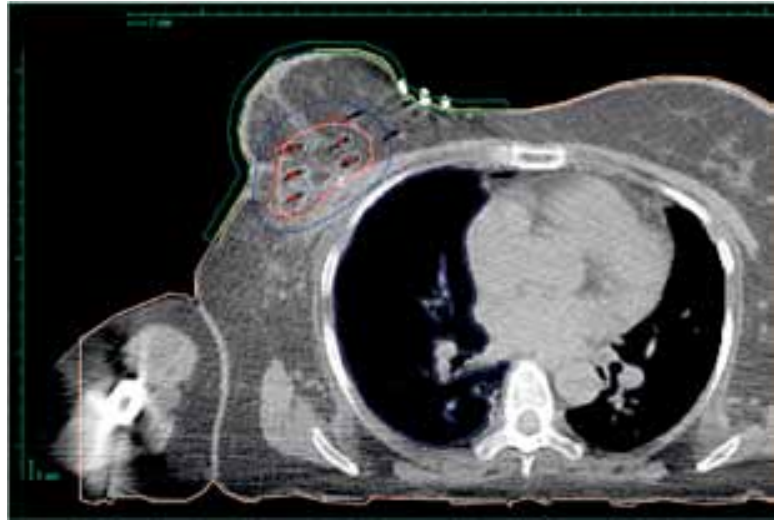

Fig. 3. The distribution of dose (isodoses) obtained after the preparation of the treatment plan, target CT cross-sections performed every 2-3 $\mathrm{mm}$
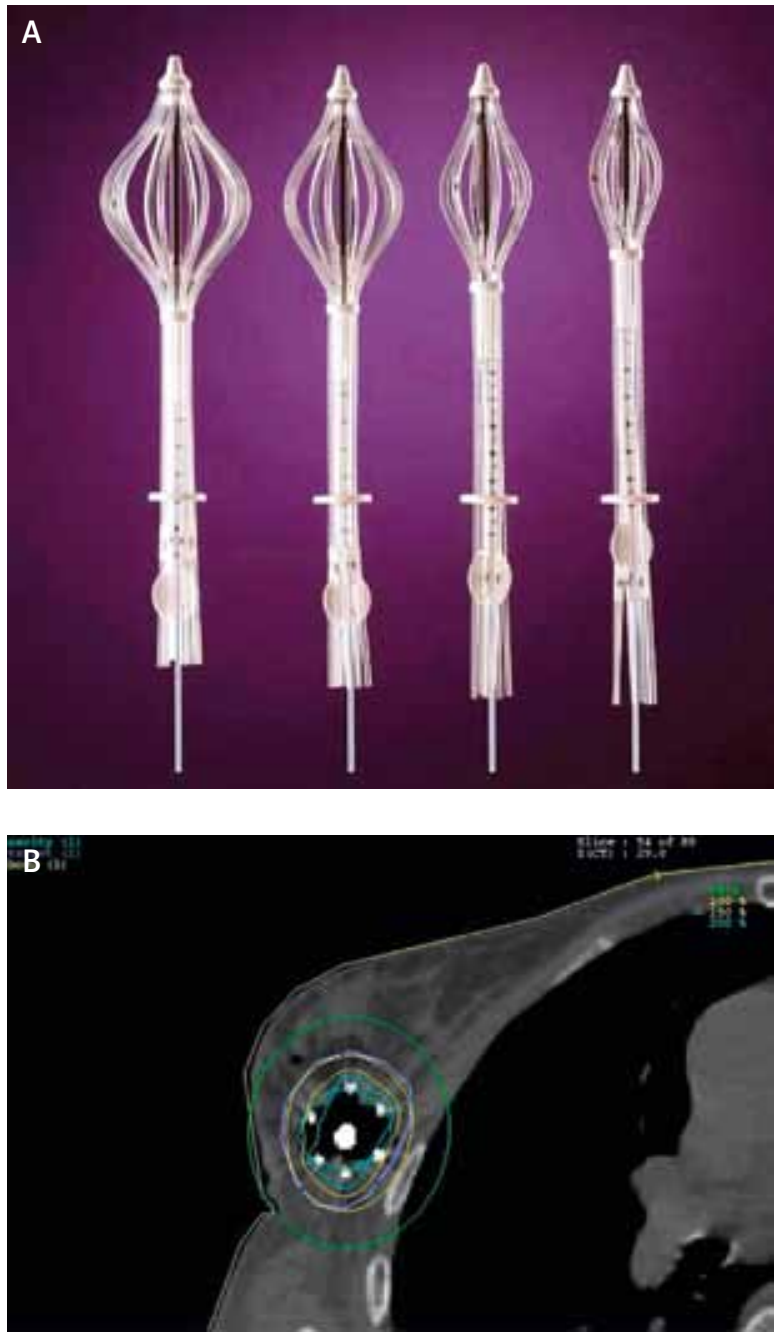

Fig. 5. A) Applicator SAVI (strut adjusted volume implant) with expanded channels (Cianna Medical ${ }^{\oplus}$ ) [36]. B) SAVI applicator, a balloon with visible isodoses [35] 
the National Surgical Adjuvant Breast and Bowel Project (NSABP) and the Radiation Therapy Oncology Group (RTOG). The objective of this trial is to compare the results of different treatment methods: WBRT, APBI with MammoSite or multicatheter interstitial BT 3D EBRT in stage 0, I and II of breast cancer [59].

Balloon brachytherapy was developed as an alternative to interstitial brachytherapy. Interstitial brachytherapy requires the experience in setting up many interstitial applicators, while using balloon brachytherapy is simpler in application. Cosmetic results after balloon brachytherapy techniques seem to be very satisfactory. A high rate of satisfactory or excellent results is worth noting. To achieve such results the proper selection of patients (large breasts, the central location of the primary tumor) is important.

\section{Technique}

The balloon applicator consists of a silicone balloon with a catheter to fill the balloon with fluid and 1 to 8 channels where a radioactive source is placed. For greater precision in most centers using this method, the balloon is fixed in the operating room under ultrasonography. Then, the applicator is fluid-filled to a volume strictly adhering to the walls of the tumor bed. Then a cross-section CT is made in order to prepare a treatment plan. Clinical target volume (CTV) includes the volume of the balloon with a margin of $1 \mathrm{~cm}$. Critical organs include the skin and lungs. In this technique HDR sources are used.

\section{Doses}

The most common dose used in a boost therapy is $10 \mathrm{~Gy}$ in one fraction. The most common treatment schemes of APBI techniques are: 1) fraction dose of 3.4 Gy two times daily at an interval of 6 hours, 10 fractions in 5 days to a total dose of $34 \mathrm{~Gy}$; 2) fraction dose of $4 \mathrm{~Gy}$ two times daily -8 fractions to $32 \mathrm{~Gy}$; 3 ) fraction dose of 4.3 Gy two times daily -7 fractions to $30.1 \mathrm{~Gy}[48,49]$.

\section{Conclusions}

The percentage of local recurrences and the cosmetic results are important arguments for the choice of brachytherapy technique. Brachytherapy as a boost after BCS and WBRT remains a standard technique for more than 20 years. Based on available results from prospective clinical trials where excellent results in selected groups of patients were achieved, it seems reasonable to use of $\mathrm{APBI}$ outside clinical trials in selected cases. This is also a conclusion of the GEC-ESTRO Breast Cancer Working Group [49]. Strict criteria for selecting patients to the early breast cancer group (low-risk group) and systematic quality control procedures (QA) must be pre- served. These recommendations may be an indication for physicians and patients to choose an APBI technique.

\section{Disclosure}

Authors report no conflicts of interest.

\section{References}

1. Skowronek J, Wawrzyniak-Hojczyk M, Ambrochowicz K. Brachytherapy in accelerated partial breast irradiation (APBI) - review of treatment methods. J Contemp Brachytherapy 2012; 4: 152-164.

2. Clarke $\mathrm{DH}$, Vicini $\mathrm{F}$, Jacobs $\mathrm{H}$, et al. High dose rate brachytherapy for breast cancer. In: Nag S (ed.). High dose rate brachytherapy: A textbook. Armonk Futura Publishing Company Inc., New York 1994; 321-329.

3. Gerbaulet A, Potter R, Mazeron J-J, et al. (eds.). The GEC ESTRO Handbook of Brachytherapy. ESTRO, Bruksela 2002.

4. Sauer G, Strnad V, Kurzeder C, et al. Partial breast irradiation after breast-conserving surgery. Strahlenther Onkol 2005; 181: 1-8.

5. Polgar C, Major T, Somogyi A, et al. Sole brachytherapy after breast conserving surgery: 4-years results of a pilot study and initial findings of a randomised Phase III trial (abstract). Radiother Oncol 2000; 55 (suppl. 1): 31.

6. Vicini F, Kini VR, Chen P. Brachytherapy of the tumour bed alone after lumpectomy in selected patients with early stage breast cancer treated with breast conserving therapy. J Surg Oncol 1999; 70: 30-40.

7. Kuske RR, Bolton JS, Mc Kinnon MP, et al. 6.5-year results of a prospective phase II trial of wide volume brachytherapy as the sole method of breast irradiation in Tis, T1, T2, No1 breast cancer (abstract). Radiother Oncol 2000; 55 (suppl. 1): 2.

8. Johansson B, Kalsson L, Liljegren G, et al. PDR brachytherapy as the sole adjuvant radiotherapy after breast conserving surgery of T1-T2 breast cancer (abstract). In: Program \& Abstracts. 10 $10^{\text {th }}$ International Brachytherapy Conference Madrid, Nucletron 2000; 127.

9. Mannino M, Yarnold J. Accelerated partial breast irradiation trials: diversity in rationale and design. Radiother Oncol 2009; 91: 16-22.

10. Fisher ER, Sass R, Fisher B, et al. Pathologic findings from the National Surgical Adjuvant Breast Project (protocol 6). II. Relation of local breast recurrence to multicentricity. Cancer 1986; 57: 1717-1724.

11. Liljegren G, Holmberg L, Bergh J, et al. 10-Year results after sector resection with or without postoperative radiotherapy for stage I breast cancer: a randomized trial. J Clin Oncol 1999; 17: 2326-2333.

12. Clark RM, Whelan T, Levine M, et al. Randomized clinical trial of breast irradiation following lumpectomy and axillary dissection for node-negativebreast cancer: an update. Ontario Clinical Oncology Group. J Natl Cancer Inst 1996; 88: 1659-1664.

13. Veronesi U, Marubini E, Mariani L, et al. Radiotherapy after breast-conserving surgery in small breast carcinoma: long-term results of a randomized trial. Ann Oncol 2001; 12: 997-1003.

14. Malmstrom P, Holmberg L, Anderson $\mathrm{H}$, et al. Breast conservation surgery, with and without radiotherapy, in women with lymph node-negative breast cancer: a randomised clinical trial in a population with access to public mammography screening. Eur J Cancer 2003; 39: 1690-1697.

15. Kurtz JM, Amalric R, Brandone $H$, et al. Local recurrence after breast-conserving surgery and radiotherapy. Frequency, time course, and prognosis. Cancer 1989; 63: 1912-1917.

16. Cholewka A, Szlag M, Białas B, et al. The importance of the implant quality in APBI - Gliwice experience. Dosimetric evaluation. J Contemp Brachytherapy 2013; 5: 227-231.

17. Chicheł A, Skowronek J, Kanikowski M. Thermal boost combined with interstitial brachytherapy in breast conserving therapy - Assessment of early toxicity. Rep Pract Oncol Radiother 2011; 16: 87-94.

18. Fisher B, Anderson S, Bryant J, et al. Twenty-year follow-up of a randomized trial comparing total mastectomy, lumpectomy and lumpectomy plus irradiation for the treatment of invasive breast cancer. N Engl J Med 2002; 347: 1233-1341.

19. Veronesi U, Cacinelli N, Mariani L, et al. Twenty-year follow-up of a randomized trial comparing breast conserving. N Engl J Med 2002; 347: 1227-1232. 
20. Kubaszewska M, Dymnicka M, Skowronek J, et al. CT-image based conformal high-dose-rate brachytherapy boost in the conservative treatment of stage I-II breast cancer - introducing the procedure. Rep Pract Oncol Radiother 2008; 13: 227-239.

21. Polgár C, Major T. Current status and perspectives of brachytherapy for breast cancer. Int J Clin Oncol 2009; 14: 7-24.

22. Polgár C, Jnvry L, Major T, et al. The role of high-dose-rate brachytherapy boost in breast-conserving therapy: long-term results of the Hungarian National Institute of Oncology. Rep Pract Oncol Radiother 2010; 15: 1-7.

23. Polgár C, Fodor J, Orosz Z et al. Electron and brachytherapy boost in the conservative treatment of stage I-II breast cancer: 5-year results of the randomized Budapest boost trial. Radiother Oncol 2002; 62 (Suppl. 1): S15.

24. Bartelink H, Horiot JC, Poortmans P, et al. Impact of a higher radiation dose on local control and survival in breast-conserving therapy of early breast cancer: 10-year results of the randomized boost vs. no boost EORTC 22881-10882 trial. J Clin Oncol 2007; 25: 3259-3265.

25. Romestaing P, Lehingue $Y$, Carrie C, et al. Role of a 10-Gy boost in the conservative treatment of early breast cancer: results of a randomized clinical trial in Lyon, France. J Clin Oncol 1997; 15: 963-968.

26. Freedman GM, Anderson PR, Hanlon AL, et al. Pattern of local recurrence after conservative surgery and whole-breast irradiation. Int J Radiat Oncol Biol Phys 2005; 61: 1328-1336.

27. Krauss DJ, Kestin LL, Mitchell C, et al. Changes in temporal patterns of local failure after breast-conserving therapy and their prognostic implications. Int J Radiat Oncol Biol Phys 2004; 60: 731-740.

28. Veronesi U, Marubini E, Del Vecchio M, et al. Local recurrences and distant metastases after conservative breast cancer treatments: partly in dependent events. J Natl Cancer Inst 1995; 87: 19-27.

29. Forrest AP, Stewart HJ, Everington D, et al. Randomised controlled trial of conservation therapy for breast cancer: 6-year analysis of the Scottish trial. Scottish Cancer Trials Breast Group. Lancet 1996; 348: 708-713.

30. Fisher B, Bryant J, Dignam JJ, et al. Tamoxifen, radiation therapy, or both for prevention of ipsilateral breast tumor recurrence after lumpectomy in women with invasive breast cancers of one centimeter or less. J Clin Oncol 2002; 20: 4141-4149.

31. Winzer KJ, Sauer R, Sauerbrei W, et al. Radiation therapy after breastconserving surgery; first results of a randomised clinical trial in patients with low risk of recurrence. Eur J Cancer 2004; 40: 998-1005.

32. Potter R, Gnant M, Kwasny W, et al. Lumpectomy plus tamoxifen or anastrozole with or without whole breast irradiation in women with favorable early breast cancer. Int J Radiat Oncol Biol Phys 2007; 68: 334-340.

33. Resch A, Fellner C, Mock U, et al. Locally recurrent breast cancer: pulse dose rate brachytherapy for repeat irradiation following lumpectomy a second chance to preserve the breast. Radiology 2002; 225: 713-718.

34. Weed DW, Edmundson GK, Vicini FA, et al. Accelerated partial breast irradiation: A dosimetric comparison of three different techniques. Brachytherapy 2005; 4: 121-129.

35. Offersen BV, Overgaard M, Kroman N, et al. Accelerated partial breast irradiation as part of breast conserving therapy of early breast carcinoma: A systematic review. Radiother Oncol 2009; 90: 1-13.

36. Njeh CF, Saunders MW, Langton CM. Accelerated Partial Breast Irradiation (APBI): A review of available techniques. Radiation Oncol 2010, 5 90; doi:10.1186/1748-717X-5-90

37. Keisch M, Arthur D, Patel R, et al. American Brachytherapy Society Breast Brachytherapy Task Group; http://www.americanbrachytherapy. org/guidelines/abs_breast_brachytherapy_taskgroup.pdf.

38. Hammer J, Mazeron J-J, Van Limbergen E. Breast Boost - Why, How, When...? Strahlenther Onkol 1999; 175: 478-483.

39. Major T, Fröhlich G, Polgar C. Assessment of dose homogeneity in conformal interstitial breast brachytherapy with special respect to ICRU recommendations. J Contemp Brachytherapy 2011; 3: 150-155.

40. Senthil G, Shunmugavel M, Veeramani S, et al. 3D CT based high dose rate interstitial brachytherapy for localized breast cancer - Plan evaluation our experience. J Contemp Brachytherapy 2009; 1: 185-186.
41. Kulik A, Łyczek J, Kawczyńska M, et al. Cosmetic effect in patients with early breast cancer treated with breast conserving therapy (BCT) and with HDR brachytherapy (HDR-BT) "boost". J Contemp Brachytherapy 2009; 1: 77-86.

42. Mansfield CM, Komarnicky LT, Schwartz GF, et al. Ten-year results in 1070 patients with stages I and II breast cancer treated by conservative surgery and radiation therapy. Cancer 1995; 75: 2328-2336.

43. Wazer DE, Kramer B, Schmid C, et al. Factors determining outcome in patients treated with interstitial implantation as a radiation boost for breast conservation therapy. Int J Radiat Oncol Biol Phys 1997; 39: 381-393.

44. Mazeron JJ, Simon JM, Crook J, et al. Influence of dose rate on local control of breast carcinoma treated by external beam irradiation plus iridium implant. Int J Radiat Oncol Biol Phys 1991; 21: 1173-1177.

45. Poortmans P, Bartelink H, Horiot JC, et al. The influence of the boost technique on local control in breast conserving treatment in the EORTC "boost vs non boost" randomised trial. Radiother Oncol 2004; 72: 25-33.

46. Fijuth J. Brachytherapy in breast cancer. J Contemp Brachyther 2009; 1: 117-120.

47. Shah $\mathrm{CH}$, Vicini F, Wazer DE, et al. The American Brachytherapy Society consensus statement For Accelerated Partial Breast Irradiation. Brachytherapy 2013; 12: 267-277.

48. Strauss JB, Dickler A. Accelerated partial breast irradiation utilizing balIoon brachytherapy techniques. Review of partial breast brachytherapy. Radiother Oncol 2009; 91: 157-165.

49. Polgár C, Van Limbergen E, Pötter R, et al. Patient selection for accelerated partial-breast irradiation (APBI) after breast-conserving surgery: Recommendations of the Groupe Européen de Curiethérapie-European Society for Therapeutic Radiology and Oncology (GEC-ESTRO) breast cancer working group based on clinical evidence. Radiother Oncol 2010; 94: 264-273.

50. Mayer A, Naszály A, Patyánik M, et al. Perioperative brachytherapy for pretreated chest wall recurrence of breast cancer. Strahlenther Onkol 2002; 178: 633-636.

51. Polgár C, Sulyok Z, Major T, et al. Reexcision and perioperative highdose-rate brachytherapy in the treatment of local relapse after breast conservation: an alternative to salvage mastectomy. J Contemp Brachytherapy 2009; 1: 131-136.

52. Cholewka A, Szlag M, Ślosarek K, et al. Comparison of 2D- and 3D-guided implantation in accelerated partial breast irradiation (APBI). J Contemp Brachytherapy 2009; 1: 207-210.

53. Serkies K, Tarnawska Z, Blukis A, et al. Comparison of two techniques of interstitial pulsed dose rate boost brachytherapy in conservative treatment of breast cancer. J Contemp Brachytherapy 2009; 1: 33-37.

54. Skowronek J, Bielęda G, Łaski P, et al. Can we improve the dose distribution for single or multi-lumen breast balloons used for Accelerated Partial Breast Irradiation? J Contemp Brachytherapy 2013; 5: 134-138.

55. Gifford KA, Nelson CL, Kirsner SM, et al. On the feasibility of treating to a $1.5 \mathrm{~cm}$ PTV with a commercial single-entry hybrid applicator in APBI breast brachytherapy. J Contemp Brachytherapy 2012; 4: 29-33.

56. Slessinger ED, Fletcher R, Das IJ. Dose perturbation study in a multichannel breast brachytherapy device. J Contemp Brachytherapy 2011; 3: 220-223.

57. Vicini FA, Douglas A, Todor D, et al. Dosimetric Improvements in Balloon Based Brachytherapy Using the Contura ${ }^{\circledast}$ Multi-Lumen Balloon (MLB) Catheter to Deliver Accelerated Partial Breast Irradiation. J Contemp Brachytherapy 2010; 2: 1-8.

58. Lee K, Quillo A, Dillon D, et al. Acute toxicity and early cosmetic outcome in patients treated with multicatheter balloon brachytherapy with skin spacing $\leq 7.0$ millimeters. J Contemp Brachytherapy 2012; 4: 8-13.

59. Perera F, Chisela F, Engel M, et al. Method of localisation and implantation of the lumpectomy cavity for high dose rate brachytherapy after conservative surgery for T1 and T2 breast cancer. Int I Radiat Oncol Biol Phys 1995; 31: 4959-4966. 